\title{
THE STATUS OF PARENCHYMATOUS ORGANS OF THE CASPIAN SEAL Phoca caspica UNDER THE CONDITIONS OF TOXICANT ACCUMULATION
}

\author{
VIKTORIA VOLODINA ${ }^{1}$, NATALIA KARYGINA ${ }^{1}$, OLGA POPOVA ${ }^{1}$, ELMIRA POPOVA ${ }^{1}$, \\ MARIIA GRUSHKO ${ }^{2}$, NADEZHDA FEDOROVA ${ }^{2}$
}

${ }^{1}$ FSBSI Caspian Research Institute for Fisheries (FSBSI “KaspNIRKh"), Savushkina 1, 414056 Astrakhan, Russian Federation; e-mail: Vo-Vik5@yandex.ru

${ }^{2}$ Astrakhan State Technical University (FSBEI HE “ASTU”) Tatishcheva 16, 414056 Astrakhan, Russian Federation; e-mail: mgrushko@mail.ru

\begin{abstract}
Volodina V., Karygina N., Popova O., Popova E., Grushko M., Fedorova N.: The status of parenchymatous organs of the Caspian seal Phoca caspica under the conditions of toxicant accumulation. Ekológia (Bratislava), Vol. 37, No. 3, p. 230-242, 2018.

The toxicological study conducted revealed high concentrations of hydrocarbons and highly toxic heavy metals in the liver and subcutaneous fat of the Caspian seal. The increased toxicant level in the fat, as compared to the liver, pointed to the disorder of organism purification processes, leading to chronic polytoxicosis and disorders of the histological structure of the internals. The studies of the morphofunctional state of the stomach of the Caspian pinnipeds revealed the following disorders: hemorrhages, edemata and necrosis of the mucous membrane, and replacement of glandular tissue with the connective tissue. The study of the small intestine of the seals identified the symptoms of catarrhal desquamatory enteritis. Epithelium dystrophy and desquamation were noted, in particular at the tops of the villi. Different types of colitis (acute, ulcerative, chronic) were found in the large intestine of the seals. Dystrophic and necrotic changes of hepatocytes were identified in the liver tissue, which pointed to the liver cell failure. The nature and extent of pathological changes in the internals and tissues of the studied animals point to the functional depression of the digestive system.
\end{abstract}

Key words: Caspian seal Phoca caspica, hydrocarbons, heavy metals, disorders, negative effect, Caspian sea.

\section{Introduction}

The problem of health protection of the marine mammals is becoming more challenging as a result of a dramatic reduction of some species. As about $40 \%$ of the species inhabiting the Caspian Sea are endemics, any threat can lead to potentially great losses of its unique biodiversity. One of these species is the Caspian seal or the Caspian phoca (Phoca caspica, Gmelin, 1788).

Pollution of the marine environment is sure to create extreme life conditions for marine mammals and fish species having a long life cycle and possessing the ability to 
accumulate information on the anthropogenic water pollution; as a result, these organisms serve as indicators of the toxic status of marine ecosystems (Attril, Depledge, 1997; Moiseenko, 2009). There are numerous instances when hydrocoles suffer from adverse effects of oil spills in the coastal sea areas (Page et al., 1998; Patin, 2001), discharges of formation waters, drilling fluids and drill cuttings (OSPAR, 2000). Among the main toxic substances that can have an adverse effect on the life of the Caspian seal are hydrocarbons (HC), especially aromatic hydrocarbons (AHC), and such heavy metals (HM) as lead $(\mathrm{Pb})$ and cadmium $(\mathrm{Cd})$. These toxic substances are defined as high-priority toxicants in the process of environmental monitoring and ecosystem impact assessment in many countries of the world. Lead and cadmium are at the top of the toxicant list as per the resolution of the Target Group on Discharges of the UN Economic Commission for Europe. The relative contribution of petroleum hydrocarbons and heavy metals to the overall anthropogenic pressure on the habitats is the highest (Tyutyunnik et al., 2000; Frumin, 2013).

The analysis of the structural and functional state of animals' organs and tissues highlights the impact of environmental factors on the organism; therefore, the objective of the paper was to study the status of tissues of digestive organs of the Caspian seal under the effect of toxicant accumulation.

\section{Material and methods}

The biological material was sampled during research field trips to the pre-winter hauling grounds of the seals near Maly Zhemchuzhny island.

The period of regular studies covered 5 years (2011-2015). Throughout this period, samples of 38 seals were collected and analyzed, the seals being of different age and gender. In addition, 70-130 individuals of common kilka (Clupeonella cultriventis caspia) were analyzed annually, as this is the main feeding source for the seal. The content of hydrocarbons and their aromatic fraction, lead and cadmium, was determined using common toxicological methods (Guidelines 213/97, 1997; NDI 05.14, 2007).

At the same time, samples of digestive organs (small and large intestine, stomach and liver) of 22 animals of different age and gender were taken for histological analysis. The samples were stored in Bouin fluid and $10 \%$ neutral formalin. The material was processed using techniques widely applied in histology (Volkova, Yeletsky, 1989). Histological sections were colored by hematoxylin-eosine and azure-II eosine as per Mallory method.

The pathological changes in the tissues and organs of hydrocoles were diagnosed and assessed in line with the method offered by Lesnikova and Chinareva (1987). Ranging scale was as follows:

- I point - Organism response not leading to its damage.

- $\quad$ II points - Slight damage. Slight vessel hyperemia.

- $\quad$ III points - Medium damage. Vessel hyperemia, perivascular and pericellular edemata, focal hemorrhages.

- IV points - Severe damage. Numerous focal hemorrhages, significant edemata, dystrophy, necrosis of about $30 \%$ of the tissues.

- $\quad$ V points - Symptoms of lethal intoxication. Significant damage of the internals under the impact of relevantly low concentrations of toxic substances, approaching chronic lethal concentrations, and almost a complete absence of damage symptoms under high lethal concentrations, but for a short exposure period.

One hundred and twenty-six animals of different age and gender were studied for the presence of parasites. Parasitological studies were conducted in line with the commonly accepted methods (Skryabin, 1928; Delyamure, Skryabin, 1965; Guidelines, 2011).

The parasite organisms were identified by means of guidelines "Trematodes of humans and animals" (Skryabin, 1947-1978), "Ranger of parasites of freshwater fish fauna of the USSR” (1984-1987), and with help of the detailed descriptions of parasites of the Caspian seal presented in the studies conducted earlier (Kurochkin, Zablotsky, 1958; Kurochkin, 1961; Delyamure et al., 1964). 


\section{Results and discussion}

Morphofunctional characteristics of an organism depend on the status of the environment and food quality. The pollutants are slowly removed from the organs and tissues, and their toxic effect grows in case of their extended impact on the marine mammals even in small concentrations (Cherkashin, 2005). The conducted toxicological study points to the high bioaccumulation capacity of the organs and tissues of the Caspian kilka, which make up to $84 \%$ of the food stock for $P$. caspica.

The northern part of the Caspian Sea is known for its oil and gas potential; a large oil-andgas-producing region is emerging here (Serebryakov, 2013). Petroleum hydrocarbons remain the main pollutants of the North Caspian. The mean long-term concentration (2006-2015) of these toxic substances in the North Caspian water exceeds the maximum allowable concentrations, adopted for fishery-significant water bodies, by more than three times (Popova et al., 2017). Starting from 2011 to 2015, the mean content of petroleum products in the North Caspian ranged significantly - from 3.2 to 7.6 MAC. In the past decade, the concentration of hydrocarbons (HC) in the organs and tissues of ichthyofauna of the Caspian Sea ranges from several dozens to several hundred $\mathrm{mcg} / \mathrm{kg}$. The content of these toxicants in the common kilka organism in 2011-2015 varied from 49.1 to $101.8 \mathrm{mg} / \mathrm{kg}$, with the maximum value in 2013 and minimum value in 2013. The aromatic hydrocarbons (AHC) were detected annually, their concentration ranging from 5.9 to $12.1 \mathrm{mg} / \mathrm{kg}$; the maximum was registered in 2012, and the minimum in 2013. It should be noted that the threshold level of aromatic component content in the total amount of HC measuring $1 \%$ and adopted as a pollution indicator (Mironov et al., 1990) was exceeded by 5.7-12.9 times.

The results of toxicological studies of the Caspian seal tissues showed, that throughout 2011-2015 the content of HC ranged from 36.4 to $90.3 \mathrm{mg} / \mathrm{kg}$, and the content of AHC varied from 4.0 to $14.3 \mathrm{mg} / \mathrm{kg}$. The aromatic component amounted to $5.0-18.2 \%$. The dynamics of hydrocarbons accumulation was not apparent; the rise in concentrations was observed both in the beginning of the study period (2011 and at the end of it (2015). The mean values of $\mathrm{HC}$ and AHC content in the seal liver for the 5-year period of study amounted to 65.9 and $9.7 \mathrm{mg} / \mathrm{kg}$ (i.e. $13.3 \%$ ) respectively; and in the seal subcutaneous tissue, it measured 64.5 and $6.8 \mathrm{mg} / \mathrm{kg}(11 \%)$.

The comparison of individuals of different age revealed higher values of hydrocarbon accumulation (both total and aromatic) in the liver and fat tissues of older seals. As compared to young animals, the increase in adult females and males was 16-37 and 12-19\% respectively. The general trend for all the age and gender generations was the fact that hydrocarbons accumulated more intensively in the fat than in the liver tissue (Fig. 1).

The age factor also affected the distribution of AHC: This toxicant concentration grew in compliance with the age of the individuals; the increase in the fat and liver was $120-190 \%$ for females and $25-52 \%$ for males. The content of aromatic compounds in liver and fat tissues depended on gender: the females (young, farrow, pregnant) accumulated these substances mostly in the subcutaneous fat, while males accumulated the pollutants in the liver (Fig. 2).

In addition to hydrocarbons, highly toxic heavy metals - lead and cadmium - are widely spread pollutants of the North Caspian. There are tough standards for limits of these pollut- 


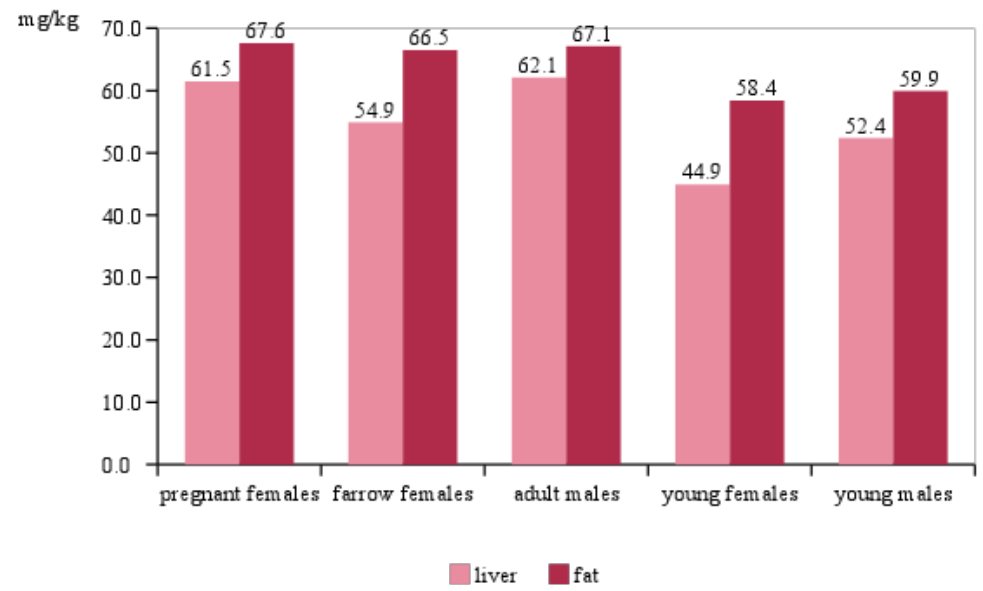

Fig. 1. The content of hydrocarbons in the liver and subcutaneous fat of the seals of different age and gender.

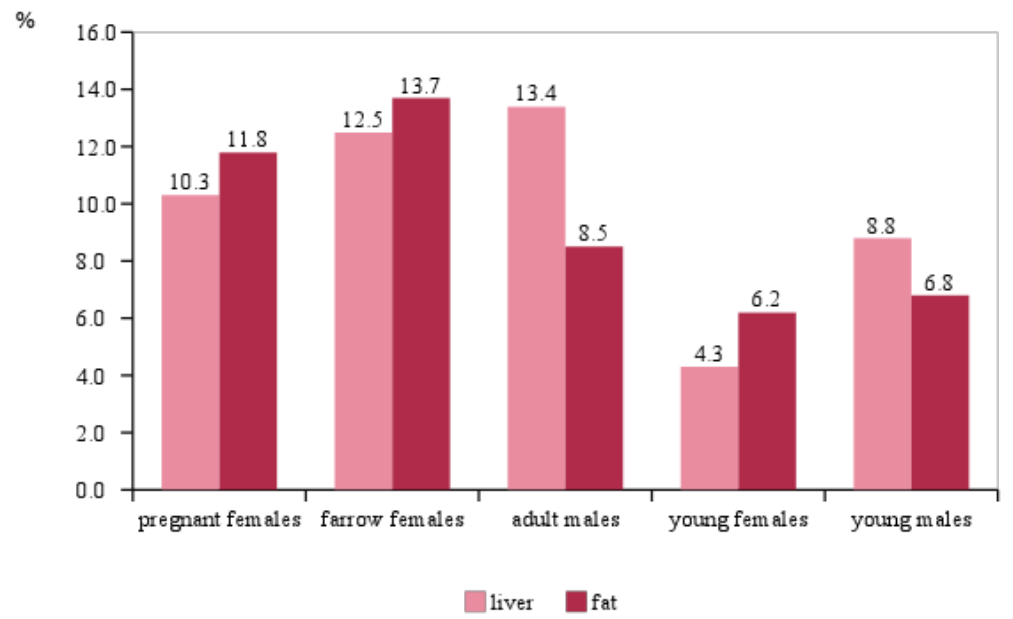

Fig. 2. The content of aromatic hydrocarbons in the liver and subcutaneous fat of the seals of different age and gender.

ants content in fishery-significant water bodies. Their long-term concentration in the North Caspian water (2006-2015) varied slightly and did not exceed the standards. Despite this fact, these toxicants accumulated in the Caspian hydrocoles in quantities that often exceeded the safe content level as per requirements of SanPiN 2.3.2. 1078-01. Thus, the mean longterm content of $\mathrm{Pb}$ and $\mathrm{Cd}$ in the organism of the common kilka amounted to 3.6 and 0.33 

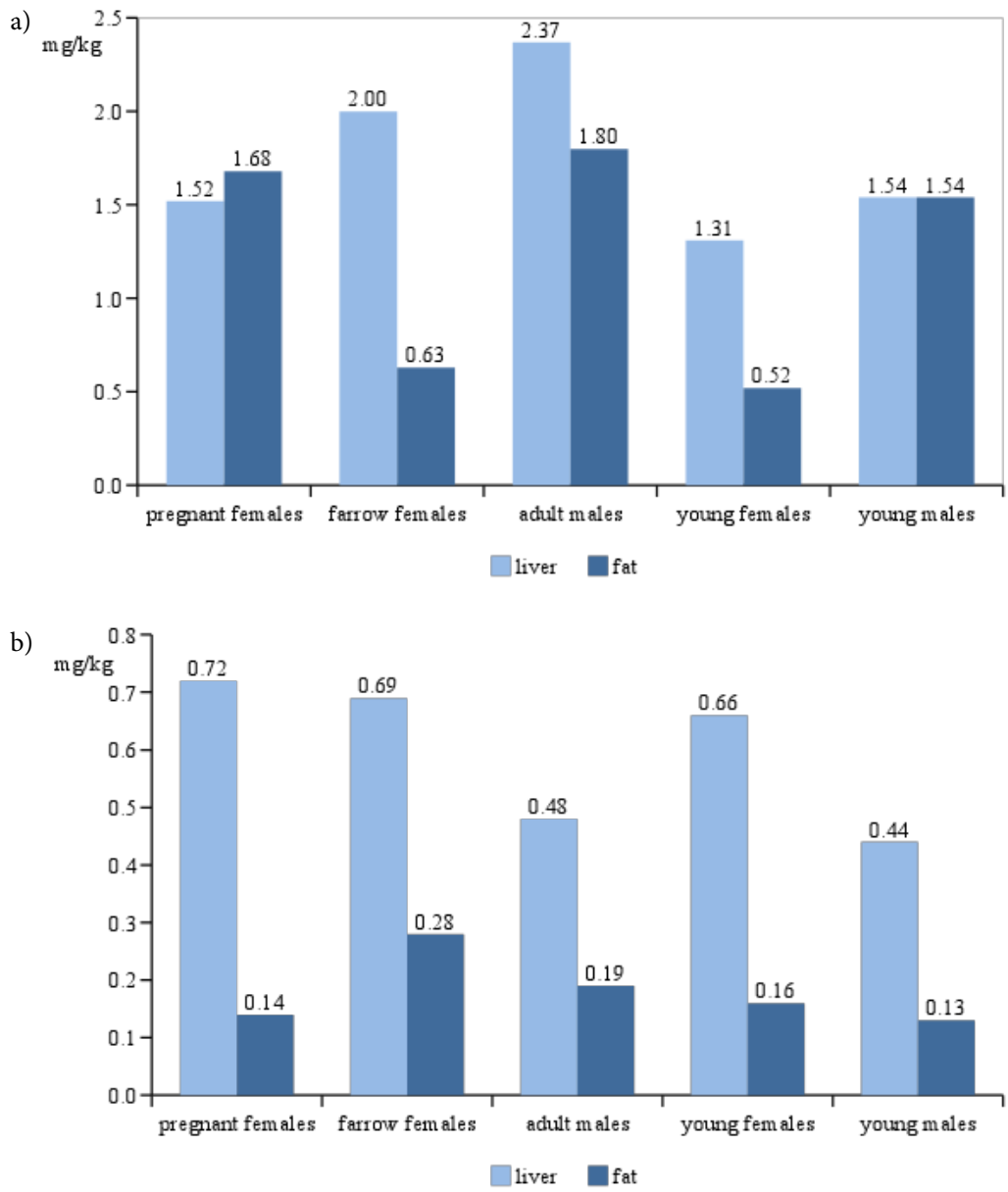

Fig. 3. The content of lead (a) and cadmium (b) in liver and fat tissues of seals of different age and gender.

$\mathrm{mg} / \mathrm{kg}$ respectively, which exceeded the accepted standards by 3.6 and 1.7 times. The values peaked in 2013. The data on the content of $\mathrm{Pb}$ and $\mathrm{Cd}$ in the tissues of the Caspian seal in 2011-2015 were of the same order as in the kilka organism, which pointed to stable accumulation. The concentrations in the liver ranged from 1.31 to 2.37 and 0.36 to $0.85 \mathrm{mg} / \mathrm{kg}$, those in the subcutaneous fat varied from 0.47 to 1.93 and 0.13 to $0.30 \mathrm{mg} / \mathrm{kg}$ respectively. It should be noted that the standards were exceeded in most cases. Lead accumulation was decreasing from 2011 to 2015, while the accumulation of cadmium peaked in 2013.

The analysis of lead concentration in the liver and subcutaneous fat tissues of the Caspian seals revealed the age-related increase by $16-23 \%$ and $10-56 \%$ for females and $17-37 \%$ and $9-46 \%$ for males respectively (Fig. 3). Maximum concentration of lead was revealed in the tissues of adult males, which was obviously conditioned by the ongoing physiological pro- 
cesses accelerating the removal of heavy metals from the organism, such as pupping, lactation and molting, in the organisms of other groups of animals. Cadmium accumulation was higher in females than in males. According to earlier studies, the highest accumulation of this metal is found in lactating females (Zakharova, 2004).

The concentration of cadmium was much higher in liver tissue as compared to subcutaneous fat in all age and gender groups. The distribution of lead content was similar, except for the pregnant females.

In general, the results of toxicological studies pointed to the chronic toxic pressure on the organisms of the animals under study.

The studies of morphofunctional status of the internals made it possible to identify a number of disorders. The histological analysis revealed that the stomach lining of the studied seals was highly hyperemic; it had rough folds and significant regions of epithelial cells exfoliation were noted. The main bulk of the proper mucous plate of the stomach consisted of numerous gastric glands. The lumen of gastric glands was poorly distinguished as a result of the edema of the proper mucous plate. The edges of the gland cells could not be determined as well. The epithelial cells flaked off the basal membrane in $30 \%$ of the sampled glands; all the cell content was concentrated in the apicalis. Most of the epithelial cells of the gland bottom had pyknotic nuclei.

Lymphocyte infiltration regions were detected in the proper mucous plate of the stomach in $86.4 \%$ of the animals. As a rule, those regions were localized in the upper top part of the mucous membrane.

Of the animals observed, $77.3 \%$ developed small hemorrhages in the fibrous loose connective tissue of the proper plate close to the stomach lumen and capillary ruptures with blood entering the gastric pits and eventually the stomach lumen. And $72.7 \%$ of the studied animals had necrotic regions in the epithelial layer of the mucous membrane. Significant regions of cirrhosis between the glands, which lead to the replacement of necrotic loci, were observed in $90.9 \%$ of the individuals (Fig. 4 ).

Submucous tissue separated from the mucous membrane by a tough muscle plate consisting of loose connective tissue and included numerous blood vessels of different diameters. The vessels were enlarged and filled with plasma. Then there was a thick muscular coat consisting of three smooth muscle layers.

Thus, according to the study of the histopathological status of the Caspian seal stomach, most samples were characterized by the following significant disorders: edemata of the mucous membrane, hemorrhages, necrosis of the mucous membrane tissues and the replacement of glandular tissue by connective tissue, which points to catarrhal gastritis.

The analysis of the seals' small intestine revealed different height, length and thickness of the intestinal villi. The tops of the villi were enlarged as compared to their bases. Necrotized regions of epithelium were identified at the tops and the sides of the villi in $90.9 \%$ of the animals under study. Some of the epithelial cells had their apical parts destroyed. The study also identified regions where epithelial cells were destroyed completely to the basal membrane. The study detected whole epithelial layers separated from the basal membrane.

Limbic cells made up the bulk of epithelium. Among them, in $95.5 \%$ of the cases enlarged goblet cells were identified (Fig. 5), at the tops of the villi in particular. 


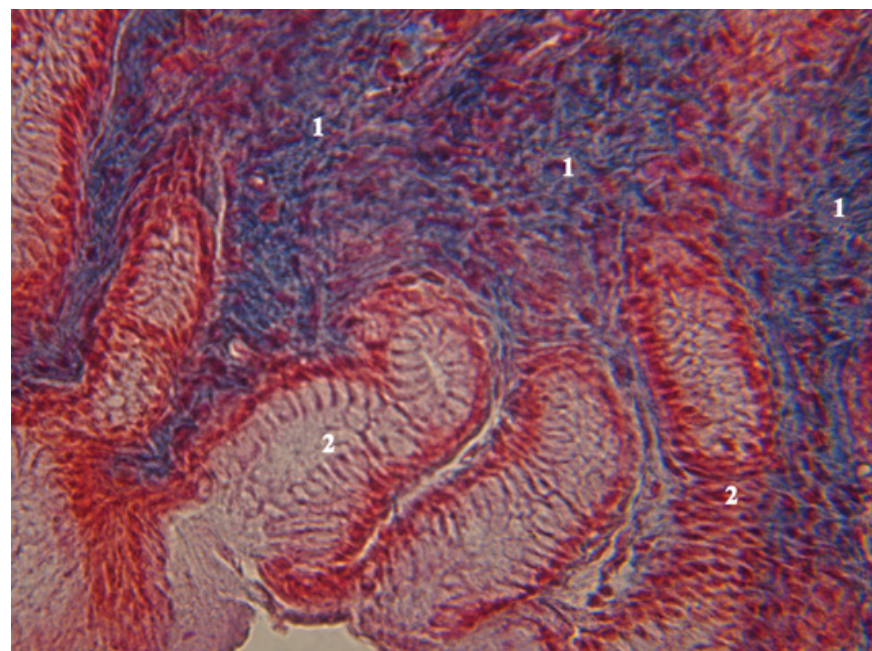

Fig. 4. Mucous membrane of a seal's stomach.

Notes: OK10 OB 40 Mallory coloring. 1. Significant regions of cirrhosis. 2. Gastric glands.

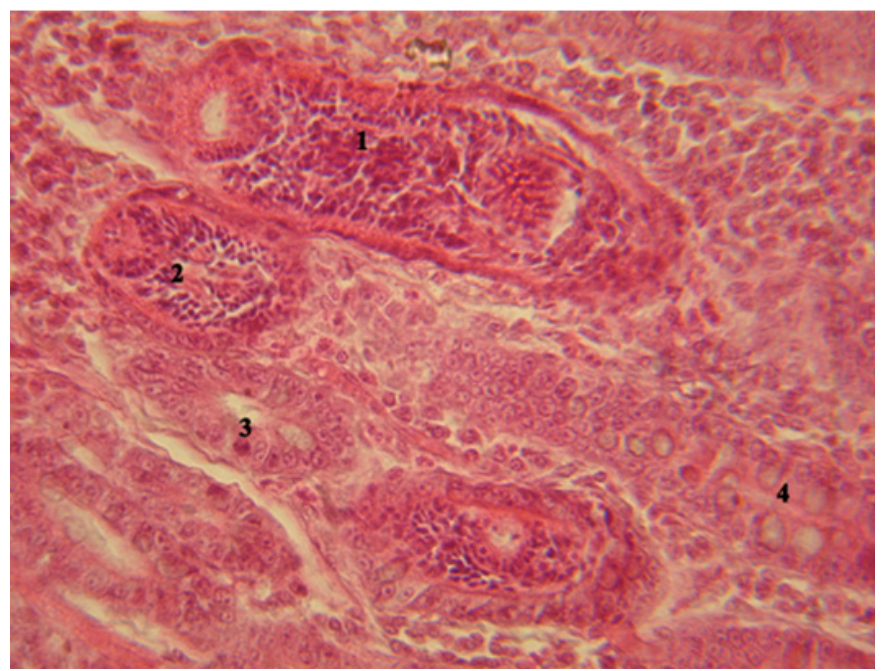

Fig. 5. Small intestine of the Caspian seal.

Notes: OK10 OB90 Hematoxylin - eosine. 1, 2. Bowel worms. 3. Intestinal crypt. 4. Goblet cells.
Limbic cells had fine-grained cytoplasm, a basally located oval nucleus with one or two nucleoli. It was difficult to clearly identify the basal membrane in $81.8 \%$ of the studied animals as a result of the edema. Intestinal crypts were lined mainly with poorly differentiated lower-lying cells as compared to epithelial cells of the intestinal villi. Some cells with acidophilic granules (Paneth cells) were identified at the edge of the villi and the crypts. The crypts were filled with mucin. Intraepithelial lymphocytes were permanently present between epithelial cells of the intestine.

The proper plate was made up of fibrous loose connective tissue with high content of lymphocytes and macrophages. The blood capillaries of the villi were unevenly enlarged, in particular at the tops of the villi; small hemorrhages were identified in the connective tissue of the tops of intestinal villi.

In some of the villi tops, the necrosis affected not only the epithelium, but the connective tissue as well. Capillary ruptures were noted at the tops of intestinal villi, which resulted in blood entering the lumen of the intestine. Of the studied seals, $81.8 \%$ had developed edemata not only in the epithelium, but also in 
the underlying connective tissue.

Then, $86.4 \%$ of the seals had enlarged limbic epithelium of the sides of intestinal villi, which led to the formation of wide epithelial plates. Invasive species such as Ciureana badamschini and Mesorchis advena were identified in all tissue specimens (Fig. 5). The prevalence of these invasive species ranged from $80 \%$ to $100 \%$. The abundance of the parasites measured a hundred thousand. Maritas were localized in the

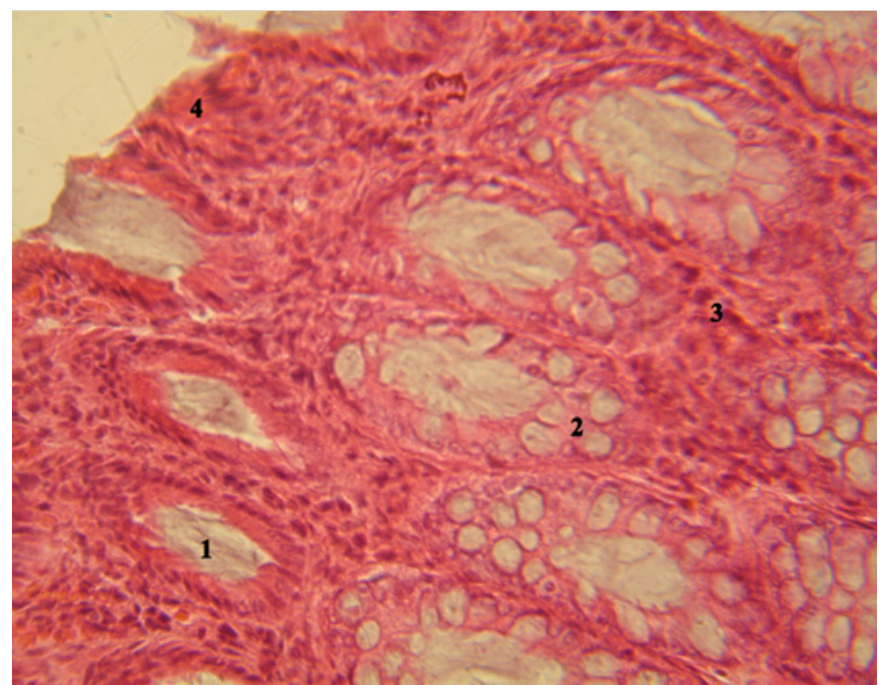

Fig. 6. Large intestine of the Caspian seal.

Notes: OK10 OB90 Hematoxylin - eosine. 1. Intestinal crypt. 2. Goblet cells. 3. Proper plate of the mucous membrane. 4 . Blood corpuscles. mucous membrane of the intestine.

In addition to trematodes, Ciureana badamschini and Mesorchis advena, the organs of the Caspian seals' digestive system were contaminated with helminthes: Anisakis schupakovi, Pseudamphistomum truncatum, Corinosoma strumosum and Eustrongylides excisus.

The results of parasitological monitoring showed that the mean long-term contamination of the Caspian seal with nematodes Anisakis schupakovi was in the range of

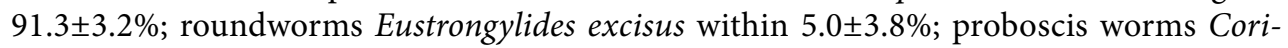
nosoma strumosum in the range $78.1 \pm 5.1 \%$; and digenetic trematodes Pseudamphistomum truncatum within $68.3 \pm 5.2 \%$. The prevalence index made $48.9 \pm 12.3,0.8 \pm 0.3,47.6 \pm 7.9$ and $2392.5 \pm 484.1$ parasites per individual respectively.

Parasites not only destroy the tissues mechanically, but they also produce a negative effect on the organism of the host, intoxicating it with metabolism products and breakdown products, which add to the toxic pressure on the organism and leads to deterioration of the organism barrier function (Lysenko, 2009).

Taking into account the impact of exogenous and endogenous toxic substances, it is logical that the intestine of the animals under study developed the symptoms of catarrhal desquamatory enteritis: plethoric and edematous mucous membrane was excessively covered with mucous exudate. $86.4 \%$ of the animals developed dystrophy. Epithelium desquamation, in particular at the tops of the villi, was recorded in $59.1 \%$ of the cases.

The results of the study of the large intestine showed that its lumen was lined with onelayer columnar limbic epithelium with a large amount of goblet cells. It where $86.4 \%$ of the animals had regions of epithelial necrosis (Fig. 6). 
The mucous membrane was strongly hyperemic; goblet cells in $90.9 \%$ of the animals were enlarged as a result of a large amount of the released secretion. In $77.3 \%$ of cases the study identified the crypts with epithelium flaking off the basal membrane and the crypts where epithelium cells were halfway destroyed. In $81.8 \%$ of cases, the study recorded the regions of different sizes with the signs of inflammation accompanied by the expansion of the infiltrate to the submucous membrane. Hemorrhages of different sizes were detected in the mucous membrane of the large intestine. These changes are typical of acute colitis.

Some of the individuals had their mucous membrane of the large intestine infiltrated by lymphocytes, neutrophils and eosinophils, the vessels were unevenly enlarged, and there were numerous erosions, which is the symptom of ulcerative colitis.

Some individuals developed chronic colitis, which was characterized by pronounced inflammatory phenomena. Thickening and desquamation of the germinal epithelium were identified. Numerous hemorrhages and erosions of the epithelial layer were noted in the mucous membrane. The study identified the regions of proliferation of the connective tissue, which replaced the regions of the intestinal crypts subject to necrosis close to the lumen in the mucous membrane in the animals under study. Atrophy and sclerosis of the mucous membrane were observed; the connective stroma of the folds and the villi was exposed. Intestinal helminths were identified in histological samples of all the animals.

The study of the Caspian seal intestine showed that the mucous membrane of the intestine was plethoric, edematous and covered with mucous exudate. In particular at the tops of the villi, epithelium dystrophy and desquamation, were observed. The signs mentioned above point to the presence of catarrhal desquamatory enteritis. The histological analysis also revealed intestinal helminths in all of the animals under study. The assessment of the scope of disorders showed that the extent of organs damage was the highest in pregnant females and corresponded on average to 3.8 scores. In descending order, they were followed by farrow females, 3.4 scores; adult males, 3.5 scores and immature males and females, 3.3 scores.

The earlier studies of the intestine of the Black Sea dolphins affected by intoxication identified acute enteritis in the animals. The symptoms were of malignant nature and were the main cause of the animals' death (Solntseva, 2002).

The status of animals' digestive organs primarily depends on the food quality. Long-term small-dose intake of toxic substances with food and water leads to deterioration of the barrier function of the organism and to inability to resist invaders (parasites, viruses, bacteria etc.). Parasites not only destroy the tissues mechanically, but they also produce a toxic effect on the organism of the host, intoxicating it with metabolic products of the living helminths and decay products of the dying ones, and trigger secondary infections (Semenova, 2001; Lysenko, 2002).

In accordance with the research carried out earlier (Semenova, 2001), the identified changes of the digestive organs of the Caspian seals were also similar to disorders emerging in the course of experimental toxic impact on the mammals.

The results of the studies of liver pointed to its exposure to pathologic changes. It should be clarified that under normal conditions of the seals' life, the level of toxicant accumulation in their liver is higher than in subcutaneous fat. It is related to the fact that the liver performs detoxication function, i.e. the processing of toxic harmful substances and their removal from 
the organism via digestive system. The disorder of liver excretory function leads to the accumulation of toxic substances in the organism, and in the fat tissue in particular. The increased content of a toxicant in the fat, as compared to liver, is a sign of disorder of the liver detoxication function and the pathological impact of the toxicant on the organism. The pathological changes identified in the liver were the congestion of the organ, the disorder of trabecular structure of the liver accompanied by

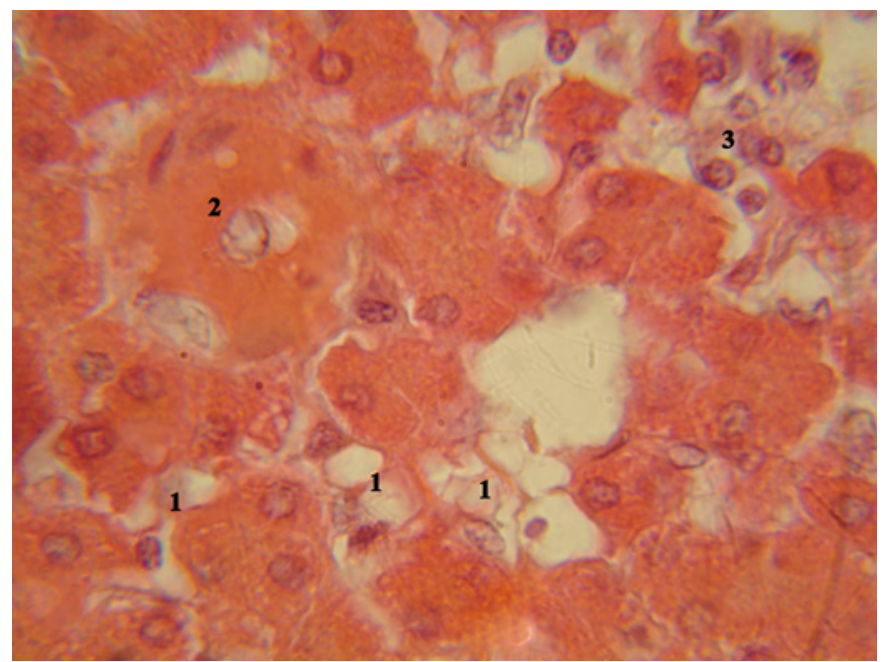

Fig. 7. Liver of the Caspian seal.

Notes: OK10 OB90 Hematoxylin - eosine. 1. Fatty degeneration of the cells. 2. Narrowed lumen of the vessel. 3. Necrosis of hepatocytes and lymphocytic infiltration. intensive fibrosis and the formation of pseudolobules consisting of proliferating hepatocytes and penetrated with interlayers of connective tissue. Most of the liver cells were enlarged; they had fine-grain cytoplasm and poorly contoured cells. The edges of the cells were poorly distinguished.

The inflammatory reaction was observed; it was accompanied by the development of necrobiotic and dystrophic processes, the edema of the connective tissue of parenchyma and local lymphocytic infiltration (Fig. 7). The infiltrates of different sizes were generally formed around the vessels.

Hepatocytes were characterized by different dystrophic changes: fatty and albuminous degeneration and degeneration of cells. The above-mentioned disorders were accompanied by the increase of liver cells on average by 1.5 times $(16.17 \pm 0.73 \mu \mathrm{m}$ vs. $11.00 \pm 0.60 \mu \mathrm{m})$. The size of the liver cells on average made $14.10 \pm 0.38 \mu \mathrm{m}$. No clear edges of liver acini could be observed as a result of the extensive edema of the organ, and the edges of hepatic turbules were vague.

The liver is known to take an active part in homeostasis dynamics, as it occupies the central place in the regulation of the metabolic process and is a link between the portal and the general blood circulation system. Maintaining the constancy of the internal milieu, the liver is involved in detoxication of xenobiotics that enter the blood with digested substances (Ezhkova, 2006). The toxic substances have an adverse effect on the structural elements of the liver, which are in primary contact with the portal circulation (Babanin et al., 2009).

Of the studied animals, $45.5 \%$ had small and large necrotic regions leading to the destructive changes of the liver parenchyma, the regions of active regeneration and proliferation of the cells, especially in the connective tissue around small and large vessels of the liver (fibro- 
sis). The lobular structure of the organ was damaged in $95.5 \%$ of the studied seals as a result of proliferative, inflammatory and destructive changes of the liver tissue. Of the animals, $72.7 \%$ had different-sized hemorrhages in the liver parenchyma.

Hepatocyte polymorphism was registered in $95.5 \%$ of cases; as a rule, it leads to the functional disorder of the liver cells as a result of uneven biosynthetic activity.

The nuclei of hepatocytes were polymorphic. The nucleus of the liver tissue cells varied within a wide range: from $3.85 \pm 0.22$ to $6.16 \pm 0.50 \mu \mathrm{m}$.

About $20 \%$ of the cells had small dark pyknotic nuclei and $60 \%$ of the cells had large light round-shaped nuclei with heterochromatin in the periphery. Akaryotic cells were also identified. In most cases the nucleus of hepatocytes was located off center as a result of dystrophic changes. The study revealed swelling of the cells and the presence of small granules of hemosiderin.

In general, the following disorders of the liver tissue of the analyzed seals were identified: inflammatory reactions, accompanied by the development of necrobiotic and dystrophic changes, edemata of the connective tissue and the parenchyma; lymphocytic infiltration as well as active proliferation of the connective tissue around the small and large vessels of the liver. The dystrophic and necrotic changes of hepatocytes lead to liver cell failure. The conducted histological study of the Caspian seal liver confirms that this organ experiences serious pressure. Similar changes were identified earlier in Black Sea dolphins affected by intoxication: dystrophic and necrotic changes of hepatocytes lead to the emergence of liver cell failure diagnosed as cirrhosis (Solntseva, 2002).

The distribution of the average score of the assessment of histopathological status of this organ was similar to that of the intestine: pregnant females, 3.75 scores; farrow females, 3.6 scores; males, 3.6 scores and immature males and females, 3.5 scores.

\section{Conclusion}

The results of toxicological studies of the Caspian seals revealed a large amount of aromatic hydrocarbons, lead and cadmium, which accumulated in their liver and the fatty tissue. The allowable level of safe content of these toxic substances was exceeded in most of the samples. The extent of toxicant accumulation depended on the age and gender of the animals.

Morphofunctional studies revealed pathological changes of stomach, small and large intestine and liver in a large amount of seals. The nature of disorder development in the organs and tissues of the seals pointed to chronic intoxication, which is logical with account of the identified high level of toxicant accumulation. The nature of pathological disorders in case of intoxication follows the pattern that the death of an animal as a result of acute intoxication is not accompanied by significant histopathological changes, which do not occur during a short time period. On the contrary, the long-term effect of a toxic substance even in small amounts, which does not lead to the death of the animal, always leads to obvious pathological changes of the internals.

The results of the study show that pathological processes depended on the structural and functional characteristics of the organs. For instance, the internals of the mammals during pregnancy experience additional functional load; therefore, it is logical that the extent of 
pathological changes in pregnant females was higher than in immature individuals. The most characteristic feature of the negative processes was the disorder of blood microcirculation in the organs. The physiological status of the Caspian seals was burdened by the presence of parasites and therefore by parasitogenic intoxication.

Thus the materials of toxicological, histological and parasitological studies pointed to the depression of the function of digestive system of the studied individuals of the Caspian seals as the pollutants accumulated in their organism.

\section{References}

Attril, M.J. \& Depledge M.H. (1997). Community and population indicators of ecosystem health: targeting links between levels of biological organization. Aquat. Toxicol., 38, 183-197. DOI: 10.1016/S0166-445X(96)00839-9.

Babanin, A.A., Zakharova, A.N., Semenova, T.V., Nesterov, E.N. \& Kaliberdenko V.B. (2009). Morphological assessment of free-radical processes in case of endotoxic liver damage (in Russian). Morphology, 3(2), 5-11.

Cherkashin, S.A. (2005). Some aspects of petroleum hydrocarbons effect on fish and crustaceans (in Russian). Vestnik DVO RAS, 3, 83-91.

Delyamure, S.L., Kurochkin, Y.V. \& Skryabin A.S. (1964). On helminthes fauna of the Caspian seal (Phoca caspica Gm.) (in Russian). In Proceedings of Astrakhan Reserve. Collection of parasitological papers, 9 (pp. 105-118). Astrakhan.

Delyamure, S.L. \& Skryabin A.S. (1965). On methodology of helminthological autopsy of marine mammals (characteristics of helminthological sampling of the pinnipeds and the cetaceans) (in Russian). Marine Mammals, 302-309. Moscow.

Ezhkova, A.M. (2006). Biogeocenosis of the system "soil-plant-animal" in different industry-related zones of the Republic of Tatarstan and its correlation with local bentonites (in Russian). Abstract of thesis, Dr.Sc. Biology, Kazan.

Frumin, G.T. (2013). Ecological toxicology (ecotoxicology) (in Russian). St. Petersburg: RSHMU.

Guidelines 213/97 (1997). Determination of the total hydrocarbons and aromatic hydrocarbons in the fatty muscle tissue, egg yolk and milk (in Russian). M. GosNIIsintezbelok.

Guidelines on sampling and primary processing of aquatic bioresources of the Caspian Basin and its habitat (in Russian) (2011). Astrakhan: KaspNIRKh.

Kurochkin, Y.V. \& Zablotskiy V.I. (1958). On helminthes fauna of the Caspian seal (1958) (in Russian). In Proceedings of Astrakhan Reserve, 4 (pp. 337-343). Astrakhan.

Kurochkin, Y.V. (1961). Helminthes fauna of the Caspian seal and its significance in the Volga Delta biocenoses (in Russian). In Proceedings of meetings on ecology and commercial marine mammal catch, 12 (pp. 233-237). Moscow.

Lesnikov, L.A. \& Chinareva I.D. (1987). Pathohistological analysis of fish status in field and experimental toxicological studies (in Russian). In Proceedings of the $1^{\text {st }}$ All-Union Symposium on the methods of ichthyologic studies (pp. 81-82). Leningrad.

Lysenko, A.Y. (2002). Clinical parasitology (in Russian). Geneva. (pp. 515-520).

Mironov, O.G., Shchekaturina, T.L., Pisareva, N.A., Kopylenko, L.R. \& Lapin B.P. (1990). Background levels of aromatic hydrocarbons in the Black sea hydrocoles (in Russian). 26(5).

Moiseenko, T.I. (2009). Water toxicology: fundamental and applied aspects (in Russian). Moscow.

NDI 05.14 - 2007. (2007) Guidelines on measurements of mass fractions of cadmium, copper, lead and zinc in the samples of hydrocoles by atomic absorption method accompanied by electrothermal atomization (in Russian). Rostov-on Don.

OSPAR (OSPAR Commission for the Protection of the Marine Environment of the North-East Atlantic) (2000). Quality status report. Region II - Greater North Sea. London: OSPAR Commission.

Page, D.S., Gilfillan, E.S., Neff, J.N., Stoker, S.W. \& Boehm P.D. (1998). Shoreline conditions in the Exxon Valdez oil spilt zone in Prince William Sound. In Proceedings on the 1998 International Oil Spill Conference (pp. 277-295).

Patin, S.A. (2001). Oil and ecology of the continental shelf (in Russian). Moscow: VNIRO Publishers.

Popova, O.V., Karygina, N.V., Lvova, O.A., Galley, E.V., Yatsun, E.V. \& Bedritskaya I.N. (2017). Current eco-toxicological status of the aquatic environment of the North Caspian (in Russian.) In Current environmental status of the environment and research aspects of efficient nature management (pp. 150-154). Materials of the 2 nd International Scientific Internet- Conference, 28 February 2017 Solenoye Zaimishche, Astrakhan Region, Russia - Compiled by N.A.Shcherbakov/ FSBSI "Caspian Research Centre of Arid Farming”. 
Ranger of parasites of freshwater fish fauna of the USSR. 3 volumes (1984-1987) (in Russian). Moscow.

Semenova, V.I. (2001). Clinical and morphological characteristics of gastroenteritis in calves and its therapy with Terfumen (in Russian). Abstract of thesis (PhD Biology), Voronezh.

Serebryakov, A.O. (2013). Oil and gas resources of the Caspian Sea (in Russian). In Geology, geography and global energy (pp. 80-88).

Skryabin, K.I. (1928). Methodology of complete helminthological autopsy of the vertebrates, including humans (pp. 1-45) (in Russian). Moscow.

Skryabin, K.I. (1947-1978). Trematodes of animals and humans (in Russian). Moscow: USSR Academy of Science.

Solntseva, G.N. (2002). The impact of pollution of the Black Sea basin on the development of pathological processes in the organs of dolphins (TURSIOPS TRUNCATUS, DELPHINUS DELPHHIS) (in Russian). In Marine mammals (pp. 433-441). Moscow.

Tyutyunnik, Y., Belokon, V. \& Blum O. (2000). Statistical conformity of the accumulation of heavy metals in depositive media and their use for monitoring of air and surface water pollution. Ekológia (Bratislava), 19(3), 331-340.

Volkova, O.V. \& Yeletsky Y.K. (1982). The basics of histological techniques (in Russian). Moscow: Meditsina.

Zakharova N.A. (2004). Accumulation level and the impact of some toxicants on the population of the Caspian seals (in Russian). Abstract of thesis (PhD Biology), ASTU, Astrakhan. 